\title{
Short communication: Mycosporine-like amino acids protect natamycin against photodegradation in milk exposed to fluorescent or light-emitting diode light
}

\author{
G. H. A. Teixeira ${ }^{1 *}$ and S. F. O'Keefe ${ }^{2}$ \\ ${ }^{1}$ Depto. de Produção Vegetal, Universidade Estadual Paulista (UNESP), Faculdade de Ciências Agrárias e Veterinárias (FCAV), \\ Campus Jaboticabal, 14.884-900, Jaboticabal, SP, Brazil \\ ${ }^{2}$ Department of Food Science and Technology, Virginia Polytechnic Institute and State University (Virginia Tech), Blacksburg 24061
}

\section{ABSTRACT}

Natamycin has been used as a natural antimicrobial in dairy products, but the poor light stability of natamycin can limit usefulness in food products. Mycosporine-like amino acids are strong UV absorbers and might be useful as an additive to decrease light-induced degradations. Therefore, the objective of this study was to evaluate the photoprotective effect of mycosporinelike amino acids (MAA) in cow milk stored under 2 lighting conditions in retail commercial display cabinets with fluorescent and high intensity light-emitting diode illumination. When milk was exposed to both fluorescent and light-emitting diode light, natamycin degradation was very fast, and only $17.1 \pm 0.9 \%$ of its original concentration was observed after $8 \mathrm{~d}$ at $4.0^{\circ} \mathrm{C}$. On the other hand, by adding MAA into milk, natamycin was retained at $82.2 \pm 0.9 \%$ and $92.2 \pm 0.9 \%$ when low and high MAA levels were used, respectively. However, high MAA levels resulted in color changes. Therefore, MAA at low levels had a photoprotective effect for natamycin stability in cow milk exposed to light in refrigerated glass containers.

Key words: natamycin, milk, mycosporine-like amino acid

\section{Short Communication}

According to Potts et al. (2017), milk consumption in the United States has declined in recent years, possibly because consumers experience off flavors in fresh milk as a result of light-induced oxidation reactions. In general, fluid milk is commercialized in packages that allow light to penetrate and react with it. Therefore, milk quality and flavors degrade in as fast as $4 \mathrm{~h}$ of

Received September 6, 2018.

Accepted February 3, 2019.

*Corresponding author: gustavo@fcav.unesp.br light-emitting diode (LED) light exposure under commercial conditions (Potts et al., 2017).

Johnson et al. (2015) reported that light-induced oxidation reactions in milk negatively affect odor and flavor, which ultimately reduces shelf-life. Photooxidation can take place in the presence of light in UV and visible wavelength regions (Webster et al., 2009) and rapidly affects consumers' milk acceptability (Duncan and Webster, 2010; Potts et al., 2017) and aroma profile (van Aardt et al., 2005).

Food packaging is a practical approach to protect food from light damage. However, consumers prefer to see the produce to evaluate quality; therefore, many foods are packaged in clear containers (Doyle, 2004), but clear or translucent packaging allows exposure to light, increasing the risk of light-induced degradation or oxidation (Duncan and Webster, 2009). Therefore, food additives are incorporated into food for functional purposes, and in many cases these ingredients can also be found occurring naturally in some foods, such as natamycin (Lindsay, 2008; Mattia et al., 2016).

Natamycin is a fungicide of the polyene macrolide antibiotic group produced by Streptomyces natalensis and related species. It is generally recognized as safe (GRAS) and has been used as a natural food additive to control the growth of yeast and mold (Mattia et al., 2016). Natamycin is a food preservative approved in the European Union, and in the United States it is permitted to be used as a preservative in dairy products (20 mg/kg), such as cheeses, shredded cheese, cottage cheese, cream cheese, sour cream, and yogurt (DelvesBroughton, 2014). However, natamycin is very sensitive to UV light (Thoma and Kübler, 1998) and photodegradation leads to biological inactivation (Dekker and Ark, 1959). Therefore, in order for natamycin to express its preservation properties in dairy produces stored in transparent packaging, something must be done to control natamycin photodegradation.

Mycosporine-like amino acids (MAA) participate in the biochemical defenses against exposure to high 
fluxes of UV light in a wide variety of marine organisms (Fleischmann, 1989; Shick et al., 1992). Mycosporinelike amino acids are polar compounds with high molar absorptivity $\left(\varepsilon=28,000-50,000 \mathrm{M}^{-1} \cdot \mathrm{cm}^{-1}\right.$; Nakamura et al., 1982; Cardozo et al., 2007), which is strongly related to the MAA photoprotective effect, which is their primary function (Dunlap et al., 1998; Torres et al., 2006).

Recent work (Teixeira et al., 2018) has reported that solid-phase extraction (SPE) purified MAA have a significant photoprotective effect on natamycin in acidified beverages stored under commercial refrigerated conditions and exposed to either fluorescent and low LED light. However, the low $\mathrm{pH}$ (3.5) of this beverage might prompt natamycin degradation itself (G. H. A. Teixeira, unpublished data). These same authors reported that at natural green tea $\mathrm{pH}(5.4)$, natamycin was less subject to photodegradation (G. H. A. Teixeira, unpublished data). Therefore, the hypothesis of our current study is that MAA might have a photoprotective effect in cow milk due to its higher $\mathrm{pH}(6.4-6.6)$. Thus, the objective of this study was to evaluate the photoprotective effect of MAA in whole dairy cow milk stored under 2 lighting conditions: fluorescent and high output LED light.

The MAA extraction was carried out according to Yuan et al., (2009). Briefly, $40 \mathrm{~g}$ of freeze-dried certified organic red dulse (Palmaria palmata L.) from Maine Coast Sea Vegetables Inc. (Hancock, ME) was extracted with $480 \mathrm{~mL}$ of methanol overnight, with 3 successive overnight extractions. Methanol extracts were filtered using Whatman no. 5 paper filters and combined. Methanol was removed by rotary evaporation (Rotavapor R-3000, Buchi Corporation, New Castle, DE) at $40^{\circ} \mathrm{C}$ and $50 \mathrm{rpm}$, until about $100 \mathrm{~mL}$ remained. The remaining methanol was washed twice with $100 \mathrm{~mL}$ of n-hexane, and hexane solutions were discarded. The methanol phase was extracted with a mixture of water $(100 \mathrm{~mL})$ and ethyl acetate $(100 \mathrm{~mL})$. The lower methanol- $\mathrm{H}_{2} \mathrm{O}$ layer was retained and extracted with $150 \mathrm{~mL}$ of 1-butanol. The upper methanol- $\mathrm{H}_{2} \mathrm{O}-1$-butanol phase was concentrated by rotary evaporation $\left(50-55^{\circ} \mathrm{C}\right)$ to obtain a light brown powder. This extraction procedure was repeated 3 times.

The MAA extracts were characterized based on UV-visible absorbance spectra obtained using a Shimadzu spectrophotometer (model UV-2500, Shimadzu Corporation, Tokyo, Japan). High-performance liquid chromatography with diode-array detection (DAD) analysis was also carried out according to Yuan et al. (2009) using an Agilent 1100 Series high performance liquid chromatogram (Agilent Technologies Inc., Palo Alto, CA). The injection volume was set to $2 \mu \mathrm{L}$ and a Macherey-Nagel Nucleosil (Oensingen, Switzerland) 100-5C18 $(250 \times 4.6 \mathrm{~mm}, 5 \mu \mathrm{m}$ particle size, $100 \AA$ pores) column was used at $30^{\circ} \mathrm{C}$. Ultra-performance liquid chromatography with mass spectrometry (UPLCMS) analysis was also performed (Yuan et al., 2005). A Waters Acquity UPLC H-Class system with QDA detector and Empower software (Milford, MA) with an AccQ-Tag Ultra C18 $(100 \times 2.1 \mathrm{~mm}, 1.7 \mu \mathrm{m}$ particle size, $130 \AA$ pore size) column was used, and the analyses were performed in scan and single ion recording modes with the goal of identifying the MAA compounds tentatively identified with C-18 HPLC-DAD.

Whole HTST pasteurized cow milk samples were obtained in a local supermarket and natamycin was added at a concentration of $21 \mathrm{mg} / \mathrm{L}$ as used by Teixeira et al. (2018). Afterward, $15 \mathrm{~mL}$ of milk was filled into $20-\mathrm{mL}$ glass bottles, capped tightly, and used immediately.

For the first experiment, clear glass flasks containing milk samples were stored in commercial display cases under fluorescent (model ONRB4, Hillphoenix, Conyers, GA) or LED (model ON5DMA8, Hillphoenix) light for up to $8 \mathrm{~d}$ at $4.0^{\circ} \mathrm{C}$. The control no light group was covered with aluminum foil. Light intensity was measured using an Upertek MK350S (Miaoli County, Taiwan), and $354.9 \pm 70.9 \mathrm{~lx}$ was recorded with fluorescent and 2,131.7 $\pm 354.9 \mathrm{~lx}$ with LED light $(\mathrm{n}=20)$. The positions of the glass flasks were randomly rotated every $24 \mathrm{~h}$ and flasks containing milk were taken from the storage on $\mathrm{d} 0,2,4$, and 8 for natamycin analysis using the procedure described by Paseiro-Cerrato et al. (2013). An external standard calibration curve was used to quantify the natamycin which was reported as milligrams per liter. The natamycin retention was expressed as a percentage of the initial concentration ( $\mathrm{d} 0$ ). The experiment was designed as a completely randomized design with 3 light treatments (control-foil, LED, and fluorescent light) and 4 repeated measurements $(0,2,4$, and 8 d) with 2 replications. The data were subjected to ANOVA and the treatment means were compared using Tukey's test at a significance level of $P<0.05$. The data were analyzed using the software Statistica (Release 4.5, StatSoft Inc., Tulsa, OK).

For the second experiment, MAA were added into milk samples to determine if MAA prevents natamycin photooxidation. Three different levels of MAA were used based on UV-visible absorbance at $330 \mathrm{~nm}$ : (1) control (0 - MAA), (2) low MAA ( 4 UV-visible absorbance), and (3) high MAA (5 times the concentration to obtain $\sim 4$ UV-visible absorbance).

The glass flasks containing the milk samples were stored in a commercial display cabinet (model ON5DMA8, Hillphoenix) with LED light exposure. In pre- 
vious work, under these conditions, rapid natamycin photodegradation occurs by $8 \mathrm{~d}$ at $4.0^{\circ} \mathrm{C}$. The control group was stored in aluminum foil-covered glass flasks to avoid light. Light exposure intensity was measured 30 times using an Upertek MK350S (Miaoli County, Taiwan) and 1,280.7 $\pm 658.9 \mathrm{~lx}$ was recorded. The positions of the glass flasks were randomly rotated every 24 $\mathrm{h}$ and flasks containing milk were taken from the storage on $\mathrm{d} 0,2,4$, and 8 for natamycin analysis according to Paseiro-Cerrato et al. (2013). The experiment was designed as a completely randomized design with 3 MAA concentrations (control, 0 MAA; low MAA, $\sim 4.0$ abs; and high MAA, $\sim 20$ abs) and 4 repeated measurements $(0,2,4$, and $8 \mathrm{~d})$ with 2 replicates. The data were subjected to ANOVA, and if main effects were significant, the means were separated using Tukey's test at a significance level of $P<0.05$. The data were analyzed using the software Statistica (Release 4.5, StatSoft Inc.).

Although $21 \mathrm{mg} / \mathrm{L}$ of natamycin was added into milk samples, we could only determine $8.9 \pm 3.0 \mathrm{mg} / \mathrm{L}$ by HPLC in milk samples, exposed or not to light, at d 0 . Based on this concentration, the percentages were calculated for each evaluation period. Therefore, natamycin solubility in milk appears much lower than in distilled water $(20-50 \mathrm{mg} / \mathrm{L})$ or matrix differences between water and milk affected extraction.

A significant interaction $(P<0.05)$ between light sources on natamycin retention was observed (Figure 1A). When milk samples were protected from light by covering the glass flasks with aluminum foil, no significant natamycin degradation was observed (Figure 1A). On the other hand, when milk was exposed to fluorescent or LED light, natamycin was rapidly degraded and the final concentration was of only $43.4 \pm$ $1.2 \%$ and $17.1 \pm 0.9 \%$ of the original level, respectively (Figure 1A).

Although natamycin shows good stability in foods in a pH range of 5 to 9 (Raab, 1972), natamycin is very sensitive to UV light (Thoma and Kübler, 1998) and photolytic reactions leads to its biological inactivation (Dekker and Ark, 1959). Even though milk has a pH around 6.4 to 6.7 , this range did not result in natamycin stability when milk was exposed to light.

According to Potts et al. (2017), retailers are replacing fluorescent lights with LED lights to reduce energy costs. In one study, LED light (4,000 lx) also caused fewer nutritional modifications due to light-induced oxidation after $24 \mathrm{~h}$ of light exposure comparted to fluorescent light $(2,200 \mathrm{~lx}$; Brothersen et al., 2016). However, LED light $(2,132 \mathrm{~lx})$ caused significantly more natamycin degradation than fluorescent light (355 lx; Figure 1A). Because the differences in the lighting includes lux intensity as well as spectral wavelengths, we cannot determine which of these caused the degradation difference in our work. However, because we used commercial display cabinets, the reported lighting would be expected to be similar in real world applications.

To protect natamycin from photoxidation, MAA were incorporated into milk samples stored under LED light because exposure under these conditions results in fast natamycin degradation (Figure 1A). Similarly, in the absence of light (light-blocked control), less natamycin photooxidation was observed, but a significant reduction in natamycin concentration on d 4 was observed in milk samples with no added MAA, which was somewhat different from the first experiment in which no significant nataymcin degradation took place (Figure 1B). By the end of the storage period, natamycin retention was of $76.6 \pm 2.8,93.9 \pm 1.1$, and $108.7 \pm 1.4 \%$ of the original natamycin level when milk samples were protected from light (control) and at low ( $\sim 4$ abs $)$ and high ( $\sim 20$ abs $)$ MAA levels, respectively (Figure 1B). Teixeira et al. (2018) reported that the incorporation of low ( $\sim 2$ abs) and high ( $\sim 4$ abs $)$ MAA levels resulted in significant natamycin photoprotection in acidified beverages (green tea infusion) when MAA were fractionated using SPE. However, the incorporation of MAA without SPE purification in milk samples presented a natamycin photoprotective effect, different from acidified green tea beverages.

When milk samples were exposed to LED light, natamycin content decreased sharply with just $9.7 \pm 1.0 \%$ of the original level remaining after $8 \mathrm{~d}$ at $4.0^{\circ} \mathrm{C}$ (Figure 1B). On the other hand, when MAA were incorporated, $82.2 \pm 4.3$ and $92.2 \pm 0.2 \%$ natamycin retention was observed at low ( $\sim 4$ abs $)$ and high $(\sim 20$ abs $)$ MAA levels, respectively (Figure 1B). The MAA incorporation into acidified beverages resulted in faster natamycin photoxidation (G. H. A. Teixeira, unpublished data), but did not happen in milk. Therefore, MAA interacting with milk components may lead to natamycin photoprotection and it should be interesting to investigate if MAA also have an effect on light-induced oxidation in milk samples exposed to light.

The chemical composition of the MAA extract was similar to Yuan et al. (2009). The UV-visible spectra showed only 1 peak at maximum absorption $\left(\lambda_{\max }\right)$ at $330 \mathrm{~nm}$, which corresponds to the presence of MAA (Carignan et al., 2009). The HPLC-DAD chromatogram presented 6 peaks (Figure 2A). The MAA identification was carried out by UPLC-MS total ion chromatogram at $245.00,333.10,289.10,303.10,347.10$, and 285.10, which corresponded to known MAA.

Incorporation of MAA into milk has a photoprotective effect on natamycin during storage under fluorescent and LED light and could conceivably be used as 

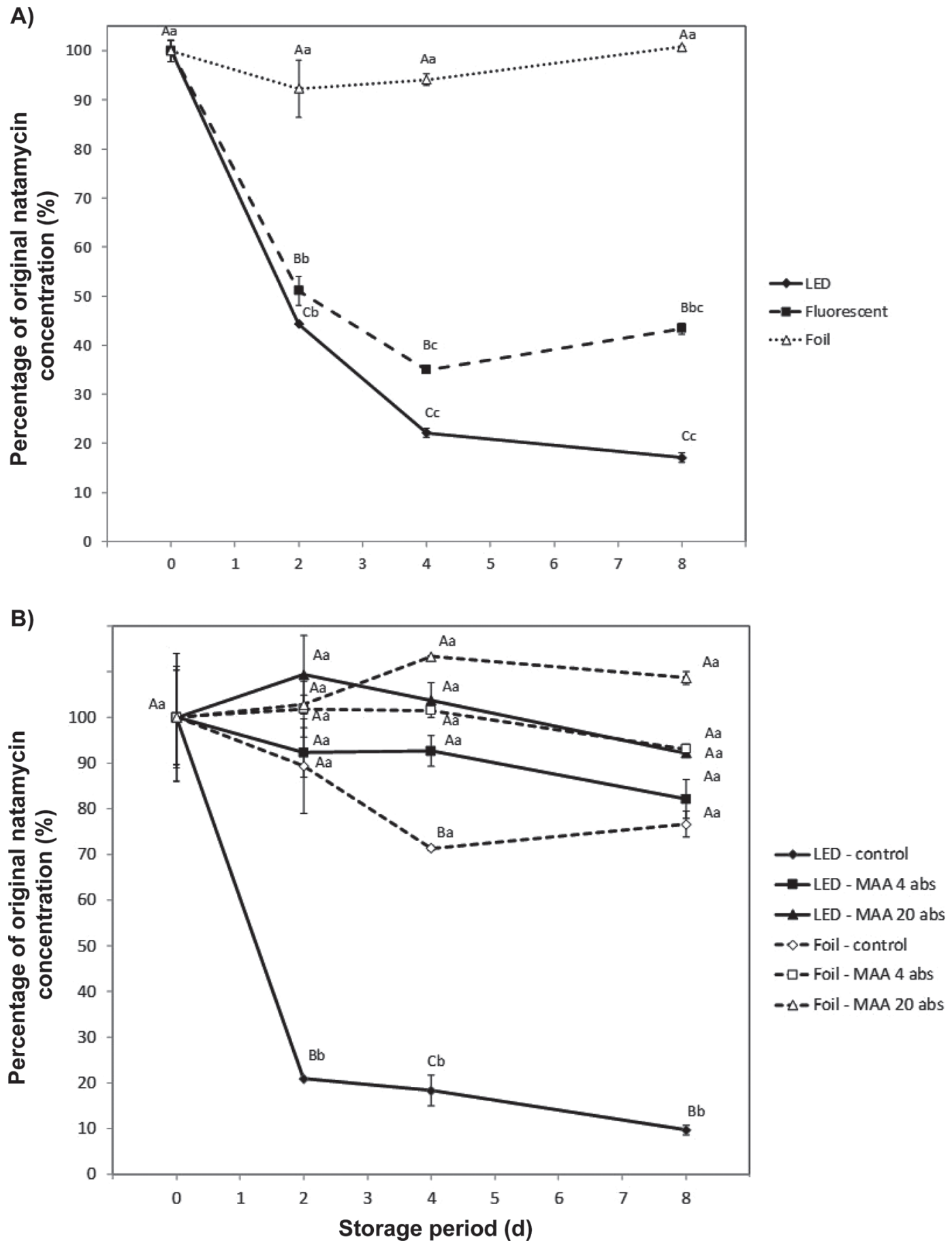

Figure 1. Natamycin retention (\%) in cow milk exposed to different light sources [control—foil, fluorescent, and light-emitting diode (LED) light] for $8 \mathrm{~d}$ at $4.0^{\circ} \mathrm{C}$ (A, experiment 1 ), and with mycosporine-like amino acid (MAA) incorporation at different levels (control-without MAA, low MAA $\sim 4.0 \mathrm{abs}$, and high MAA $\sim 20 \mathrm{abs}$ ) and exposed to LED light for $8 \mathrm{~d}$ at $4.0^{\circ} \mathrm{C}$ (B, experiment 2). The bars represent the SD of 2 replicates. abs = absorbance. Average values with the same uppercase letters $(\mathrm{A}-\mathrm{C})$ within storage period are not statistically different by Tukey's test $(P<0.05)$. Average values with the same lowercase letters $(\mathrm{a}-\mathrm{c})$ within treatment are not statistically different by Tukey's test $(P<0.05)$.

an additive to protect milk from light-induced oxidation reactions. However, the interactions between MAA and milk components are still an open field of study, and future studies should address mechanisms.

\section{ACKNOWLEDGMENTS}

The authors thank the Fundação de Amparo à Pesquisa do Estado de São Paulo (FAPESP) for pro- 


\section{(A)}

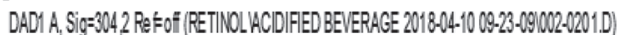

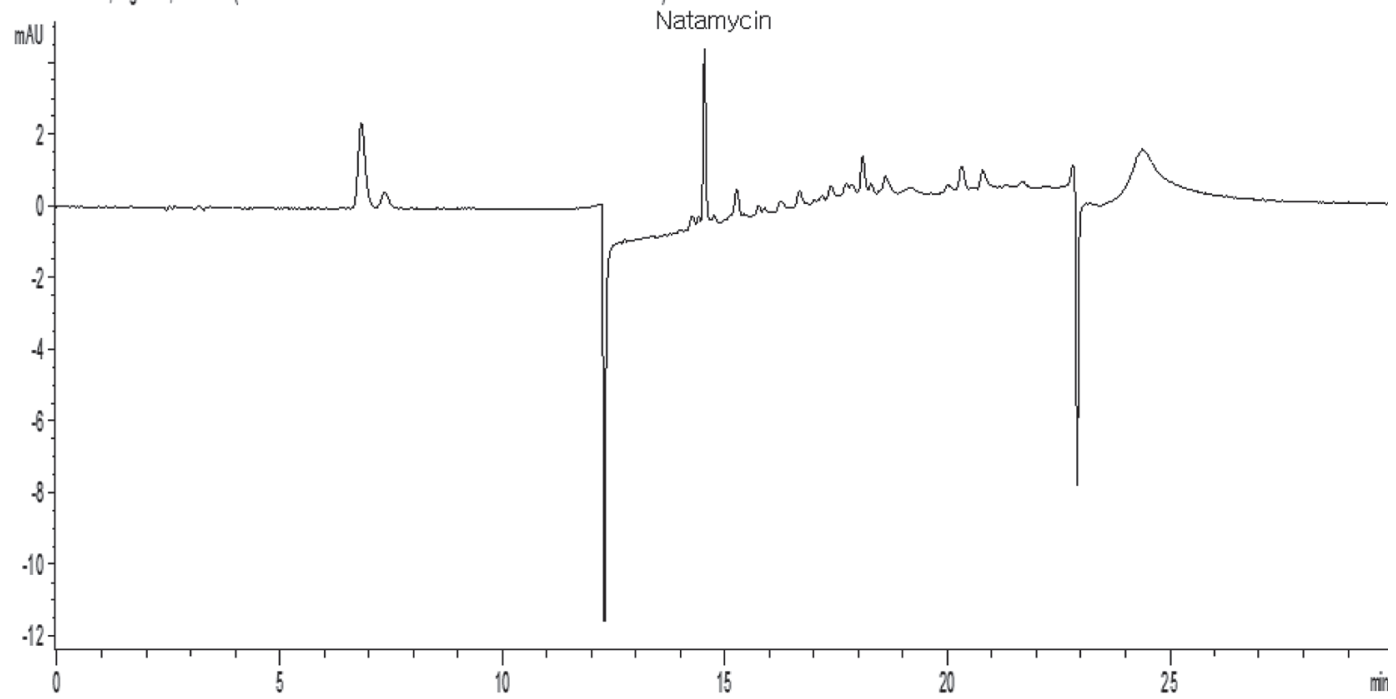

(B)

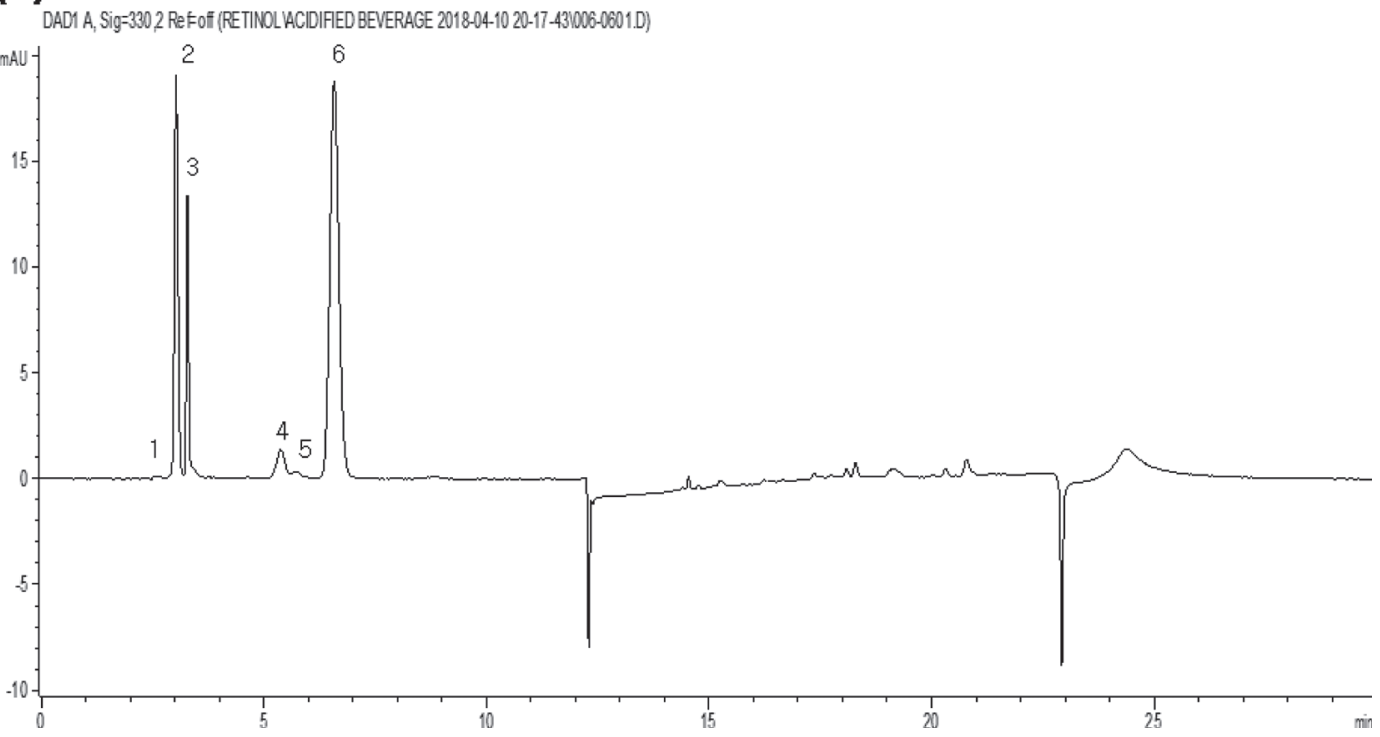

Figure 2. (A) High-performance liquid chromatography-diode-array detection chromatogram of natamycin and (B) mycosporine-like amino acids (MAA) in cow milk samples.

viding the BPE fellowship of the first author (proc. 2016/25214-1). Funding was also provided in part by the Virginia Agricultural Experiment Station and the Hatch Program of the National Institute of Food and Agriculture, United States Department of Agriculture (Washington, DC).

\section{REFERENCES}

Brothersen, C., D. J. McMahon, J. Legako, and S. Martini. 2016. Comparison of mill oxidation by exposure to LED and fluorescent light. J. Dairy Sci. 99:2537-2544.
Cardozo, K. H. M., T. Guaratini, M. P. Barros, V. R. Falcão, A. P. Tonon, N. P. Lopes, S. Campos, M. A. Torres, A. O. Souza, P. Colepicolo, and E. Pinto. 2007. Metabolites from algae with economical impact. Comp. Biochem. Physiol. C Toxicol. Pharmacol. 146:60-78.

Carignan, M. O., K. H. M. Cardozo, D. Oliveira-Silva, P. Colepicolo, and J. I. Carreto. 2009. Palythine-theonine, a major novel mycosporine-like amino acid (MAA) isolated from the hermatypic coral Pocillopora capitata. J. Photochem. Photobiol. B 94:191-200.

Dekker, J., and P. A. Ark. 1959. Protection of antibiotic pimaricin from oxidation and ultraviolet light by chlorophyllin and other compounds. Antibiot. Chemother. (Northfield) 9:327-332.

Delves-Broughton, J. 2014. Permitted preservatives - natamycin. Pages 87-91 in Encyclopedia of Food Microbiology. 2nd ed. C. A. Batt and M. L. Tortorello, ed. Academic Press, London, UK. 
Doyle, M. 2004. Consumers have long list of packaging wishes and pet peeves. Food Drug Packag. 68:24-28.

Duncan, S. E., and J. B. Webster. 2009. Sensory impacts of foodpackaging interactions. Adv. Food Nutr. Res. 56:17-64.

Duncan, S. E., and J. B. Webster. 2010. Oxidation and protection of milk and dairy products. Woodhead Publishing Ltd., Cambridge, UK.

Dunlap, W. C., B. E. Chalker, W. M. Bandaranayake, and J. J. Wu Won. 1998. Nature's sunscreen from the Great Barrier Reef, Australia. Int. J. Cosmet. Sci. 20:41-51.

Fleischmann, E. M. 1989. The measurement and penetration of ultraviolet radiation into tropical marine water. Limnol. Oceanogr. 34:1623-1629.

Johnson, D. S., S. E. Duncan, L. M. Bianchi, H. H. Chang, W. N. Eigel, and S. F. O'Keefe. 2015. Packaging modifications for protecting flavor of extended-shelf-life-milk from light. J. Dairy Sci. 98:2205-2214.

Lindsay, R. C. 2008. Food additives. Pages 689-749 in Fennema's Food Chemistry. 4th ed. S. Damodaran, K. L. Parkin, and O. R. Fennema. CRC Press, Boca Raton, FL.

Mattia, A., C. Cerniglia, and J. Baines. 2016. WHO food additives series: 48 safety evaluation of certain food additives and contaminants natamycin (pimaricin). Accessed Feb. 17, 2017. http://www .inchem.org/documents/jecfa/jecmono/v48je06.htm.

Nakamura, H., J. Kobayashi, and Y. Hirata. 1982. Separation of mycosporine-like amino acids in marine organisms using reversed-phase high-performance liquid chromatography. J. Cromatogr. 250:113118.

Paseiro-Cerrato, R., P. Otero-Pazos, A. R. B. Quirós, R. Sendón, I. Angulo, and P. Paseiro-Losada. 2013. Rapid method to determine natamycin by HPLC-DAD in food samples for compliance with EU food legislation. Food Control 33:262-267.

Potts, H. L., K. N. Amin, and S. E. Duncan. 2017. Retail lighting and packaging influence consumer acceptance of fluid milk. J. Dairy Sci. 100:146-156.
Raab, W. 1972. Natamycin (Pimaracin). Its properties and possibilities in medicine. Georg Thieme Publishers, Stuttgart, Germany.

Shick, J. M., W. C. Dunlap, B. E. Chalker, A. T. Banaszak, and T. K. Rosenzweigh. 1992. Survey of ultraviolet radiation-absorbing mycosporine-like amino acids in organs of coral reef holothuroids. Mar. Ecol. Prog. Ser. 90:139-148.

Teixeira, G. H. A., L. Morelli, S. Ma, A. Stewart, and S. F. O'Keefe. 2018. Photoprotective effect of mycosporine-like aminoacids (MAA) extracts on natamycin, saffron carotenoids, and epigallocatechin gallate in acidified beverages exposed to different light sources. Int. J. Food Sci. Technol. 54:440-450. https://doi.org/10 $.1111 /$ ijfs. 13956 .

Thoma, K., and N. Kübler. 1998. New results in the photostability of antimycotics. Pages 116-133 in Drugs: Photochemistry and Photostability. A. Albini and E. Fasani, ed. The Royal Society of Chemistry, Cambridge, UK.

Torres, A., C. D. Enk, M. Hochberg, and M. Srebnik. 2006. Porphyra-334, a potential natural source for UVA protective sunscreens. Photochem. Photobiol. Sci. 5:432-435.

van Aardt, M., S. E. Duncan, J. E. Marcy, T. E. Long, S. F. O'Keefe, and S. R. Nielsen-Sims. 2005. Aroma analysis of light-exposed milk stored with and without natural and synthetic antioxidants. J. Dairy Sci. 88:881-890.

Webster, J. B., S. E. Duncan, J. E. Marcy, and S. F. O'Keefe. 2009. Controlling light oxidation in milk by blocking riboflavin excitation wavelengths by interference. J. Food Sci. 74:S390-S398.

Yuan, Y. V., M. F. Carrington, and N. A. Walsh. 2005. Extracts from dulse (Palmaria palmata) are effective antioxidants and inhibitors of cell proliferation in vitro. Food Chem. Toxicol. 43:1073-1081.

Yuan, Y. V., N. D. Westcott, C. Hu, and D. D. Kitts. 2009. Mycosporine-like amino acids composition of the edible red alga, Palmaria palmate (dulse) harvested from the west and east coasts of Grand Manan Island, New Brusnwich. Food Chem. 112:321-328. 